\title{
Utilization of Numerical Techniques to Predict The Thermal Behavior of Wood Column Subjected to Fire Part A: Using Finite Element Methods to Develop Mathematical Model for Wood Column
}

\author{
Mohamed ElShayeb ${ }^{1,}$, , Faisal A.Fairag ${ }^{2}$, Zolman Hari ${ }^{3}$, Norhaida Ab Razak ${ }^{1}$, \\ Jacqueline Eng Ling Siang ${ }^{1, b}$, Fazril Ideris ${ }^{1}$ \\ ${ }^{1}$ Mechanical Eng. Department, College of Eng. ${ }^{3}$ Science \& Maths Department, \\ UNIVERSITI TENAGA NASIONAL, M'Sia \\ ${ }^{2}$ Mathematic Department, KING FAHD UNIVERSITY OF PETROLEUM AND MINERALS. \\ asmohamed@uniten.edu.my, bjacqueline@uniten.edu.my
}

\section{Keywords: Mathematical Modeling; Finite Element Method; Temperature History}

\begin{abstract}
The mathematical model to predict the temperature history for wood column is needed in order to determine its fire resistance when exposed to fire. In this paper, an intelligent methodology called Finite Element Method (FEM) of performing analysis for the square and circular wood columns by virtually or artificially developing a temperature history mathematical model. Numerical simulation model has been developed for the wood column by using two-dimensional mathematical model. The two-dimensional mathematical model was developed by using Galerkin's Weighted Residual technique. This model focuses on the regional material of the wood column for describing its thermal behavior. When the temperature history in a column and relevant materials properties are known, the strength of the column can be calculated at any time during fire. Therefore, the development of the temperature history mathematical model is a must before any further study to be carried out for the wood columns. The flow of convection will result in minimal increase in the rate of heat energy reaching the column core. The analysis shows that the temperature of the column increases with respect to the duration of exposure to fire.
\end{abstract}

\section{Calculation Procedure}

Division of cross section into elements. Analysis is done for two types of columns, namely square and circular columns. Due to its symmetrical property, only one-quarter of the cross section is considered. Then, the cross sectional area of the one-quarter of the cross section is subdivided into a number of elements, i.e. into many triangular elements. The triangular element is shown in Fig.1 below. Fig. 2 and Fig. 3 shows the quarter meshing for circular and square cross section column.

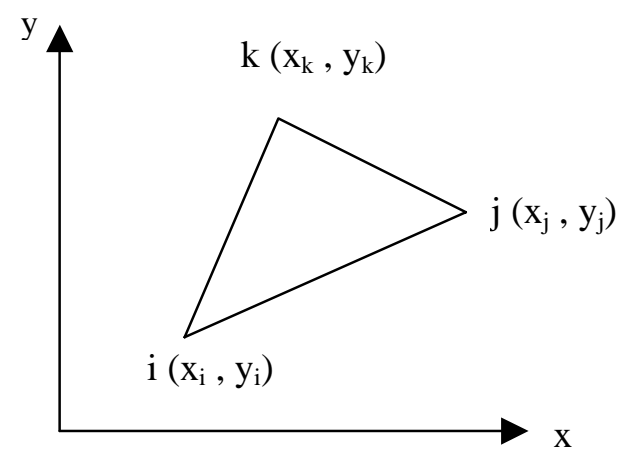

Fig. 1 A Triangular Element

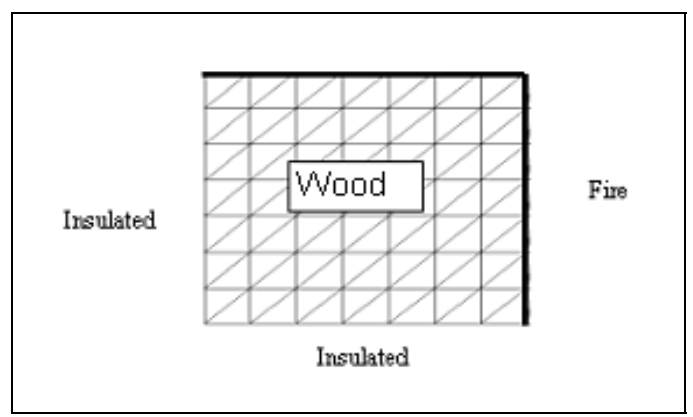

Fig. 2 Quarter meshing of square column

The heat flux from the fire is assumed to be transferred into the cross section through either one or two of the boundary by convection and radiation modes. Once the heat flux enters the boundary, these heat fluxes will be transferred into the inner part of the cross section through conduction mode.The evaluation of the temperature in finite element method is based on elementwise consideration.Fig. 4 shows the shematic general two dimensioanl heat conduction problem. 


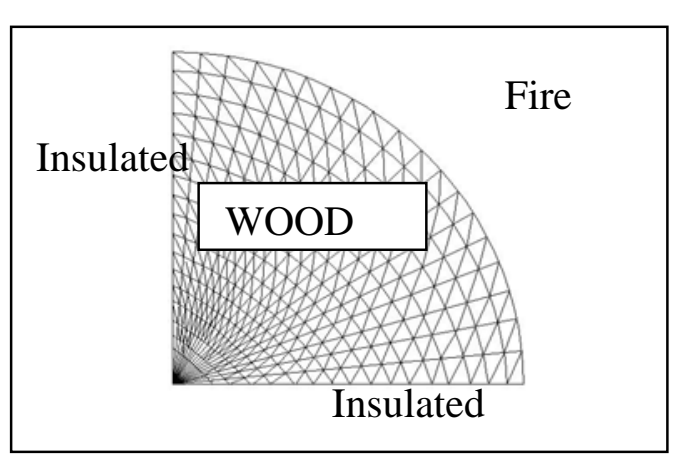

Fig.3: Quarter meshing of circular crosssection

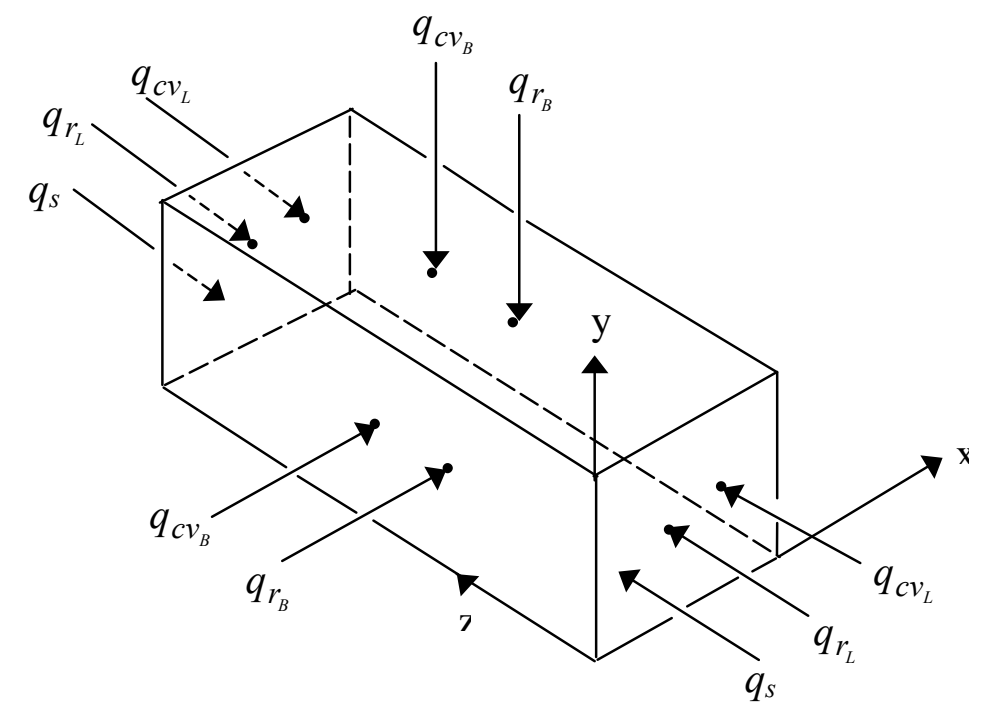

Fig. 4: Schematic General two-dimensional Heat Conduction Problem

By using the unsteady state partial differential equation,

$$
\frac{\partial}{\partial x}\left(k t \frac{\partial T}{\partial x}\right)+\frac{\partial}{\partial y}\left(k t \frac{\partial T}{\partial y}\right)+h\left(T_{f}-T\right)+\varepsilon \sigma\left(T_{f}^{4}-T^{4}\right)+q_{s}+Q t=\rho c t \frac{\partial T}{\partial t}
$$

where:

$\frac{\partial T}{\partial x}=$ temperature gradient in $\mathrm{x}$-direction, ${ }^{\circ} \mathrm{C} / \mathrm{m}, \frac{\partial T}{\partial y}=$ temperature gradient in y-direction, ${ }^{\circ} \mathrm{C} / \mathrm{m}$

$k=$ thermal conductivity, $\mathrm{W} / \mathrm{m} .{ }^{\circ} \mathrm{C}, \quad t=$ thickness, $\mathrm{m}$

$h=$ sum of the convective heat transfer coefficients on the one lateral faces of $\mathrm{z}$-axis, $\mathrm{W} / \mathrm{m}^{2} .{ }^{\circ} \mathrm{C}$

$T_{f}=$ fire temperature, ${ }^{\circ} \mathrm{C}, \quad T=$ body temperature, ${ }^{\circ} \mathrm{C}$

$\varepsilon=$ sum of the one lateral surface along z-axis surface emissivities on the two lateral faces, dimensionless

$\sigma=$ Stefan-Boltzmann constant, $\mathrm{W} / \mathrm{kg} \cdot \mathrm{K}$

$Q_{s}=$ the sum of the heat fluxes imposed on the one lateral faces of z-axis, $\mathrm{W}$

$Q=$ the heat generation per unit time and volume, $\mathrm{W} / \mathrm{s}$

$\rho=$ density, $\mathrm{kg} / \mathrm{m}^{3}, c=$ specific-heat, $\mathrm{J} / \mathrm{kg} .{ }^{\circ} \mathrm{C}, \frac{\partial T}{\partial t}=$ temperature gradient with time, ${ }^{\circ} \mathrm{C} / \mathrm{s}$

To suit the formulation into finite element analysis, Galerkin's weighted residual method is applied with the residual

$$
\left\{\mathrm{R}^{\mathrm{e}}\right\}=\left[\frac{\partial}{\partial \mathrm{x}}\left(\mathrm{kt} \frac{\partial \mathrm{T}}{\partial \mathrm{x}}\right)+\frac{\partial}{\partial \mathrm{y}}\left(\mathrm{kt} \frac{\partial \mathrm{T}}{\partial \mathrm{y}}\right)+\mathrm{h}\left(\mathrm{T}_{\mathrm{f}}-\mathrm{T}\right)+\varepsilon \sigma\left(\mathrm{T}^{4}-\mathrm{T}_{\mathrm{r}}^{4}\right)+\mathrm{q}_{\mathrm{s}}+\mathrm{Qt}-\rho \mathrm{ct} \frac{\partial T}{\partial \tau}\right]
$$

The Galerkin's weighted residual method is applied to Eqn. (2) in a very straightforward manner. The integration of the shape function times the residual will minimize the residual to zero as follow: $\int_{e}[N]^{T}\left\{R^{e}\right\} d V=\int_{A^{e}}[\mathrm{~N}]^{\top}\left[\frac{\partial}{\partial \mathbf{x}}\left(\mathrm{kt} \frac{\partial \mathrm{T}}{\partial \mathbf{x}}\right)+\frac{\partial}{\partial \mathbf{y}}\left(\mathrm{kt} \frac{\partial \mathrm{T}}{\partial \mathbf{y}}\right)+\mathrm{h}\left(\mathrm{T}_{\mathrm{f}}-\mathrm{T}\right)+\varepsilon \sigma\left(\mathrm{T}_{\mathrm{f}}^{4}-\mathrm{T}^{4}\right)+\mathrm{q}_{\mathrm{s}}+\mathrm{Qt}-\rho \mathrm{ct} \frac{\partial \mathrm{T}}{\partial t}\right] \mathrm{dxdy}=0$

where : $\left\{R^{(e)}\right\}=$ the residual contributed by element (e) to the final system of equations

$[N]^{T}=$ the transpose of the element shape function

By applying the Green’s Theorem on the term involving second-order derivatives yields:

$\int_{\mathrm{e}}[\mathrm{N}]^{\top}\left\{\mathrm{R}^{\mathrm{e}}\right\} \mathrm{dV}=\int_{C^{e}}[N]^{T} k t \frac{\partial T}{\partial x} n_{x} d C-\int_{A^{e}} \frac{\partial[N]^{T}}{\partial x} k t \frac{\partial[N]}{\partial x}\{T\}^{e} d x d y+$ 


$$
\begin{aligned}
& \int_{C^{e}}[N]^{T} k t \frac{\partial T}{\partial y} n_{y} d C-\int_{A^{e}} \frac{\partial[N]^{T}}{\partial y} k t \frac{\partial[N]}{\partial y}\{T\}^{e} d x d y+\int_{A^{e}}[N]^{T} h[[N]\{T\}] d x d y-\int_{A^{e}}[N]^{T} h T d x d y+ \\
& \int_{A^{e}}[N]^{T} \varepsilon \sigma\left[[N]\{T\}^{e}\right]^{3}[N]\{T\}^{e} d x d y-\int_{A^{e}}[N]^{T} \varepsilon \sigma T^{4} d x d y+\int_{A^{e}}[N]^{T} q_{s} \cdot d x d y+\int_{A^{e}}[N]^{T} Q t \cdot d x d y \\
& -\int_{A^{e}}[N]^{T} \rho c A[N] \frac{\partial\{T\}^{e}}{\partial \tau} d x d y=0
\end{aligned}
$$

By taking into consideration the boundary conditions, integration is performed upon of all the terms in Eq. 4 to obtain composite element stiffness matrix $[K]^{e}$, composite nodal force vector $\left\lfloor f^{e}\right\rfloor$ and capacitance matrix $[\mathrm{C}]^{\mathrm{e}}$ from the Galerkin's solution.The final form for the element wise or local

approximation will be in the form of: $[\mathrm{C}]^{\mathrm{e}}\left\{\dot{T}^{e}\right\}+[\mathrm{K}]^{\mathrm{e}}\{T\}^{\mathrm{e}}=\{\mathrm{f}\}$

where $\quad\left\{\dot{T}^{e}\right\}=\frac{\partial\{T\}}{\partial t}$, matrix of unknown variable, where $T$ is temperature and $\mathrm{t}$ is the time.

$$
[\mathbf{K}]^{\mathbf{e}}=[\mathrm{K}]_{\mathrm{xx}}^{\mathrm{e}}+[\mathrm{K}]_{\mathrm{yy}}^{\mathrm{e}} \text {, element stiffness matrix }
$$

Assemblage of the element matrices to the global matrices of the domain. The assemblage step is necessary in all finite element analysis. In this step the region being analyzed is put back together or assembled from the individual elements comprising it. The assemblage step is based on the principle of compatibility; i.e. a particular node on any given element must be identical to those associated with the same node on each element that shares this node. The global must be assembled to form the assemblage stiffness matrix, assemblage capacitance matrix, and assemblage nodal force vector. The basic idea behind this step is that the unknown parameter function must have the same value at any given node regardless of the element containing the node. Assembling the stiffness matrix, heat capacitance matrix, and the force vector of all elements of the domain, into global matrices as follows: $[K]_{g}\{T\}+[C]_{g}\{\dot{T}\}=\{f\}_{g}$

where

$$
\begin{aligned}
& {[K]_{g}=[K]^{1}+[K]^{2}+[K]^{3}+\ldots \ldots \ldots \text {. etc. }} \\
& =\text { global stiffness matrix, }(\mathrm{n} \times \mathrm{n}) \\
& \{T\}=\text { unknown temperature, (n } \mathrm{x} 1) \\
& {[C]_{g}=[C]^{1}+[C]^{2}+[C]^{3}+\ldots \ldots \ldots \text { etc. }} \\
& \text { =global heat capacitance matrix, }(\mathrm{n} \times \mathrm{n}) \\
& \begin{array}{l}
\{\dot{T}\}=\text { rate of change of temperat } \\
\text { respect to time, }(\mathrm{n} \times 1) \\
\begin{aligned}
\{f\}_{g} & =\{f\}^{1}+\{f\}^{2}+\{f\}^{3}+\ldots \ldots . . \text { etc. } \\
& =\text { global force vector },(\mathrm{n} \times 1)
\end{aligned}
\end{array}
\end{aligned}
$$

Time Dependent Solution. The solution method used in this problem is the Backward Difference Scheme (BDS). The BDS means the derivative, i.e. time $(t)$, is written in the backward direction (with respect to time) and the time step is not zero, $\Delta \mathrm{t} \neq 0$.

Results and Discussions. The completed finite element equations for the above temperature history mathematical models will be incorporated into FORTRAN computer program. The computer program will compute the temperature history by using the Backward Difference Scheme solution with the maximum floating-point precision.

There are four important parts in the computer program to achieve the objective:

a. Development of meshing program.

b. Development of temperature history program.

c. Development of strength determination program.

d. Development of post-processing program.

The general dimension of the column is given in Fig. 5 and the meshing is given in Fig. 2. 
Table 1: Comparison column center temperature and endurance time at different boundary conditions for square column (Keruing wood, and applied

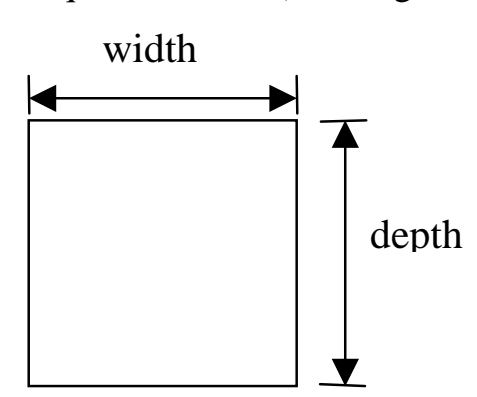

Fig.5: Square wood column

\begin{tabular}{|c|c|}
\hline Type of boundary & $\begin{array}{c}\text { Temperature of } \\
\text { column center } \\
\text { after } 30 \text { min. }\end{array}$ \\
\hline $\begin{array}{c}\text { Fire from One } \\
\text { side }\end{array}$ & $20^{\circ} \mathrm{C}$ \\
\hline $\begin{array}{c}\text { Fire from Two } \\
\text { sides }\end{array}$ & $24^{\circ} \mathrm{C}$ \\
\hline $\begin{array}{c}\text { Fire from Three } \\
\text { sides }\end{array}$ & $25^{\circ} \mathrm{C}$ \\
\hline $\begin{array}{c}\text { Fire from } \\
\text { all sides }\end{array}$ & $27^{\circ} \mathrm{C}$ \\
\hline
\end{tabular}

Temperature history of square column. The numbers of the selected elements are 5 and 25 (on the column surface), 125 and 146 (at the first third of column quarter), 280, 291(at the second third of the column quarter) and element 436 (at the column center). Table 1 summarizes the comparison of the columns center temperature at different fire boundary for 30 minute. Fig. 6 and Fig. 7 show the temperature history for the selected element at different fire boundary. This results shows that the wood has a very low thermal conductivity. From the temperature history graphs, at the fire boundary the temperature starts to increase rapidly at $110^{\circ} \mathrm{C}$. The reason is that some of the fire energy at the beginning of pyrolysis is consumed to evaporate moisture; later on this fire energy will raise the surface column temperature. It is observed from Fig. 6 that the intersection of the twotemperature history profiles for element 25 on the column boundary and element 291 inside the column. Element 25 is closer to fire than element 291, this is why the temperature of element 25 starts to increase at the starting of pyrolysis. It is observed that the rate of temperature increases for element 25 is starting to decrease after 70 minutes, on contrary to element 291. It is suggested that the reason behind this, is due to that element 291 has more sides subjected to heat conduction than element 25. Also element 25 has one side subjected to atmospheric temperature, which will dissipate some of the heat especially at higher temperature.

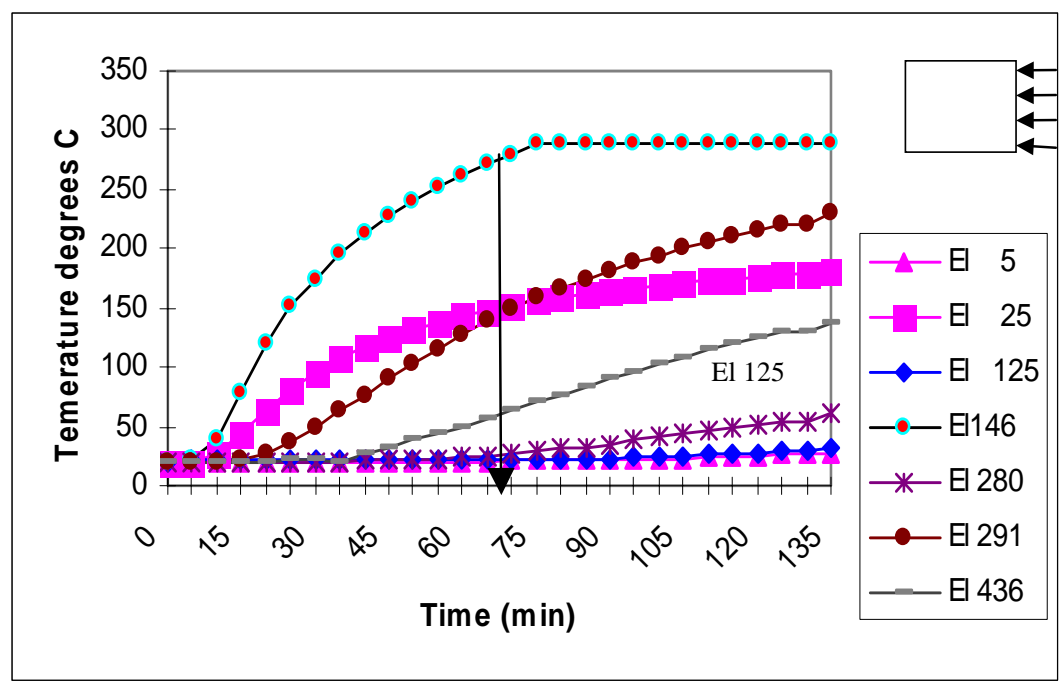

Fig.6: Temperature variation of selected elements on the square column surrounded with fire from one side for Malaysian Keruing timber 


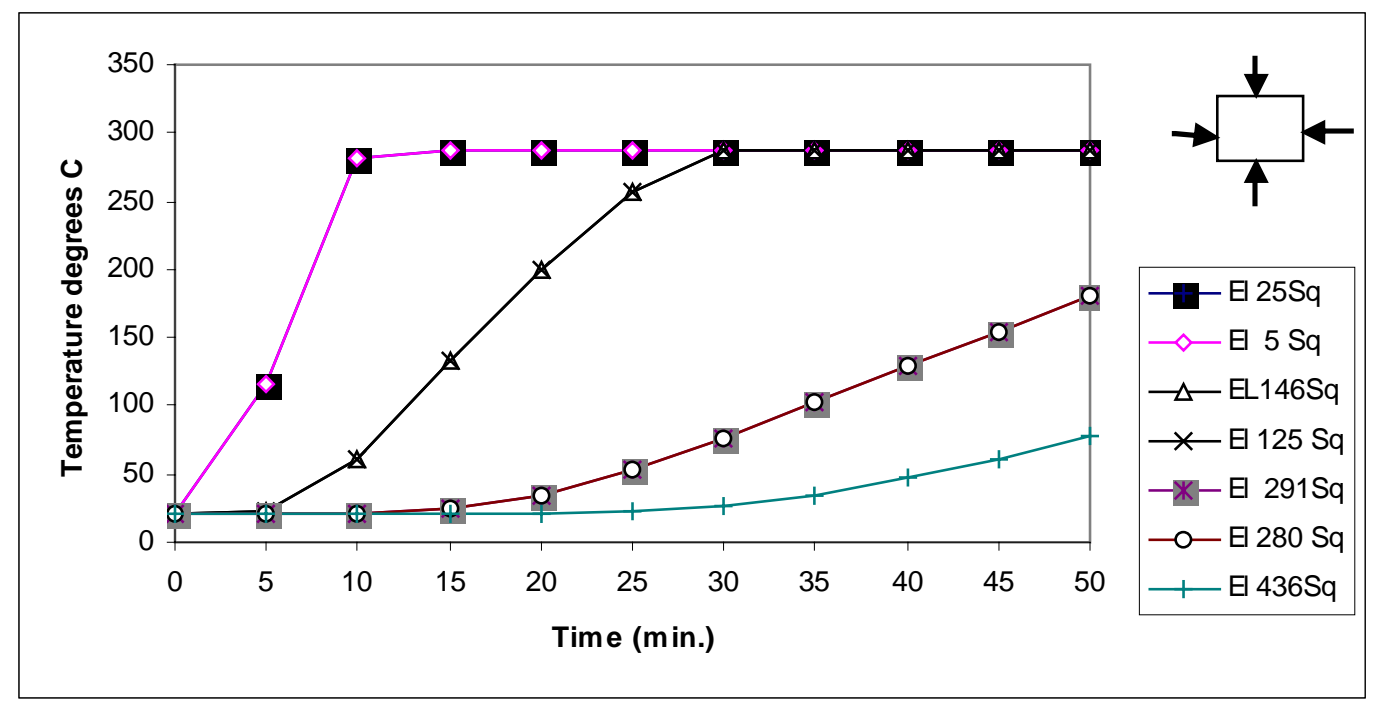

Fig.6: Temperature variation of selected elements on the square column surrounded with fire from all sides for Malaysian Keruing timber

Temperature history for circular cross section column. The sensitivity analysis for this column will be done such that the fire boundary is surrounding the cross-section. The column diameter is $214 \mathrm{~mm}$. The temperature histories for the selected elements are presented in Fig. 8. The quarter meshing of circular cross-section column is shown in Fig. 2. The charred area for the quarter of the column is $5924 \mathrm{~mm}^{2}$.

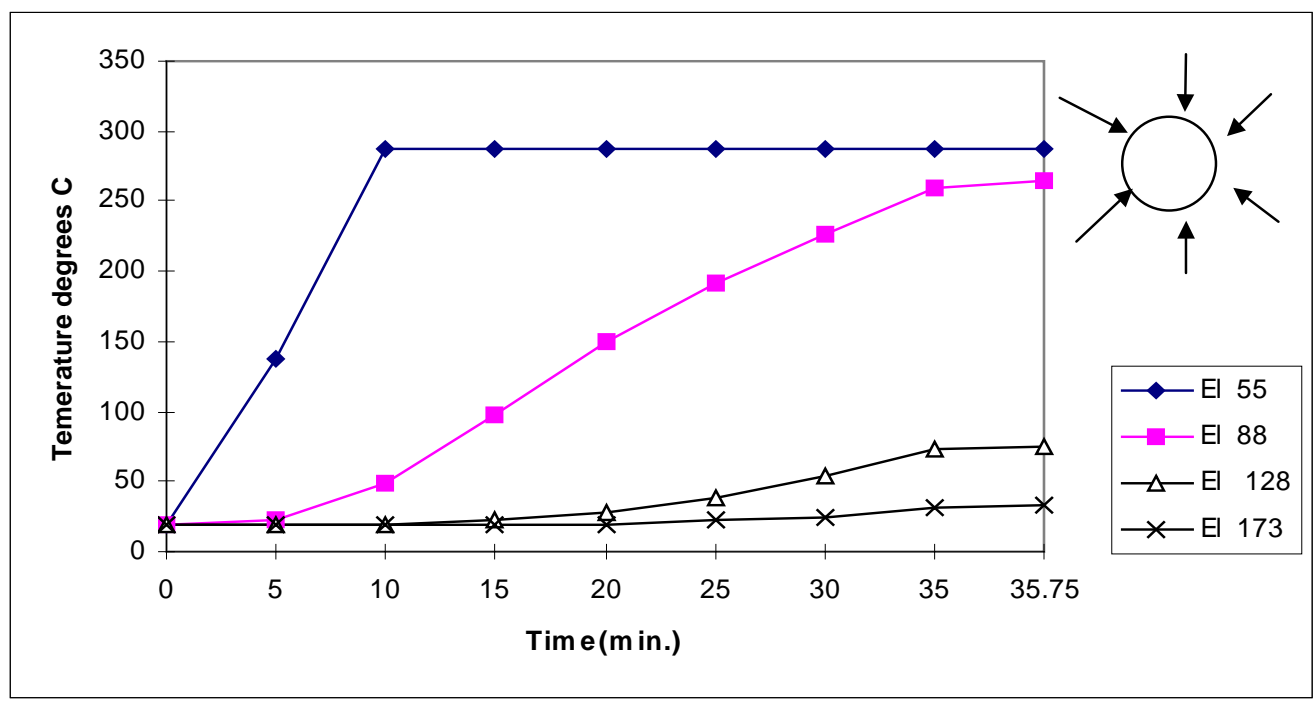

Fig.8: Temperature variation of selected elements on circular cross section column surrounded with fire from all sides (Malaysia Keruing timber)

Comparison of columns center temperature for different column cross sections surrounded with fire from all sides. The temperature results for different configurations of the column center are shown in Fig 9. The highest column center is square column. The simulation results indicate that the best cross section is the circular cross section. The least circumference is the circular column because the area exposure to fire is least.

\section{Conclusion}

A two-dimensional numerical simulation model based on Finite Element Methods had been developed for wood column. This mathematical model was later converted into computer models using FORTRAN programming language for simulation purposes as shown in results, discussion 
and presented in this research paper as Part A. The later subsections (Part B, [5], and C, [6]) of the research papers will discuss the analysis of the column's temperature and fire resistance.

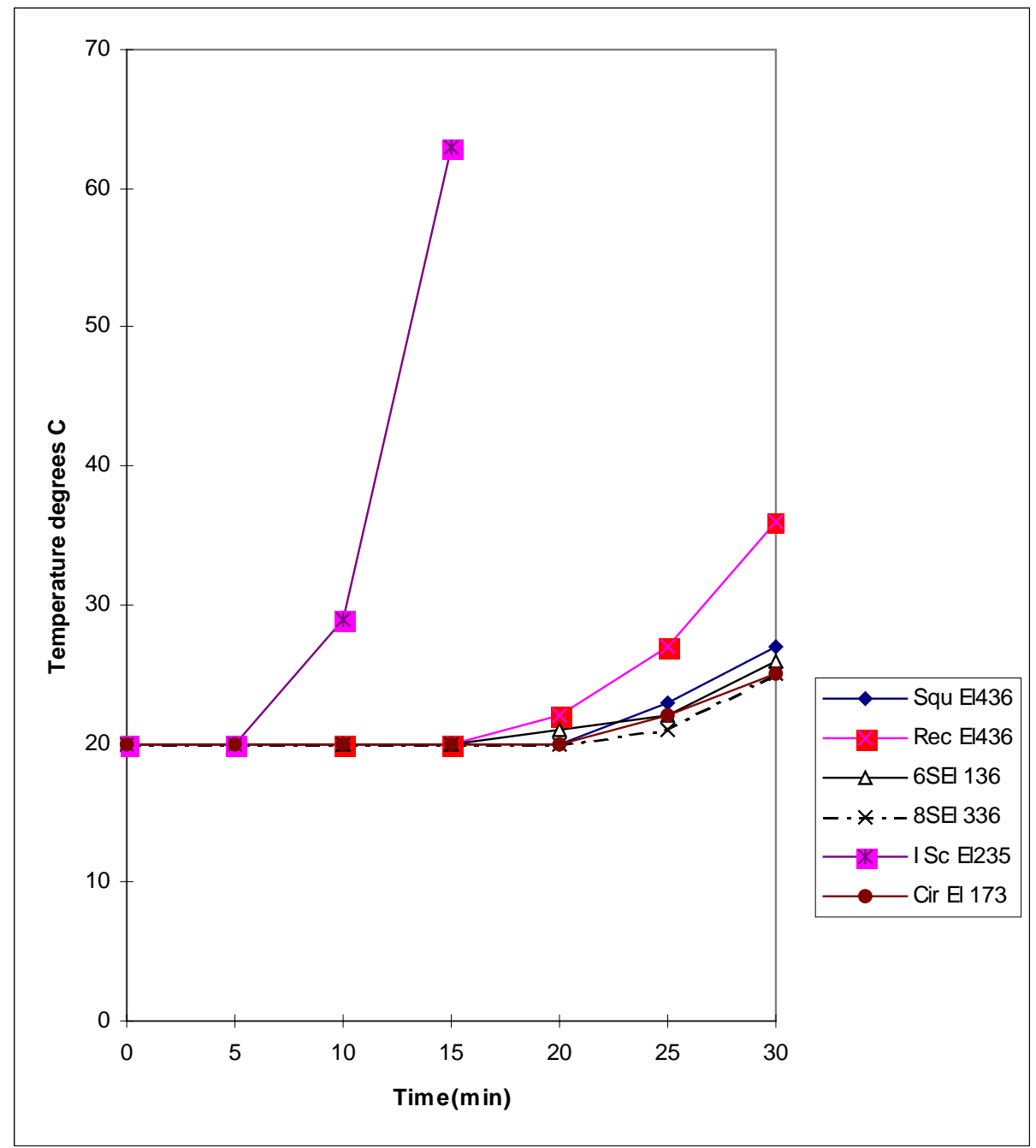

Fig.9: Temperature variation for different column configuration at the column center (Malaysian Keruing timber)

\section{References}

[1] M. Elshayeb, Y.K. Beng, Application of Finite Difference and Finite Element Methods for Thermal Problems, Univ. Malaysia Sabah (2001)

[2] F.N. Istas, Estimation of Strength of Engineering Component Exposed to Fire, Master of Science in Mechanical Engineering, Universiti Teknologi Malaysia (1997)

[3] A.H. Mian, Using Numerical Techniques for Predicting the Fire Resistance of Steel Column during Fire, MSc. diss., Dept. of Mech. Engineering, Universiti Teknologi Malaysia (2000)

[4] H.A.E. Gouda, Performance of Structural Wood Column Exposed to Fire, MSc. Diss., Dept of Mech. Engineering, Universiti Teknologi Malaysia (1999)

[5] Mohamed ElShayeb, Faisal Fairag, Zolman bin Hari, Norhaida bt Ab Razak,Jacqueline Eng Ling Siang, Utilization of Numerical Techniques to Predict The Thermal Behavior of Wood Column Subjected to Fire Part B: Analysis of Column Temperature and Fire Resistance, Proceeding of FEOFS 2005, Bali, Indonesia.

[6] Mohamed ElShayeb, Faisal Fairag, Zolman bin Hari, Fazril Ideris,Jacqueline Eng Ling Siang, Norhaida bt Ab Razak' Utilization of Numerical Techniques to Predict The Thermal Behavior of Wood Column Subjected to Fire Part C: Sensitivity Analysis, Proceeding of FEOFS 2005, Bali, Indonesia. 